\title{
Utilizing the Resource of Twins Reared Apart: Their Distribution Across Nine Provinces or Cities of China
}

\author{
Wenjing Gao, ${ }^{1}$ Bin Zhou, ${ }^{1}$ Weihua Cao, ${ }^{1}$ Jun Lv, ${ }^{1}$ Canqing Yu, ${ }^{1}$ Shengfeng Wang, ${ }^{1}$ Zengchang Pang, ${ }^{2}$ \\ Liming Cong, ${ }^{3}$ Zhong Dong, ${ }^{4}$ Fan Wu, ${ }^{5}$ Hua Wang, ${ }^{6}$ Xianping $\mathrm{Wu}^{7}{ }^{7}$ Guohong Jiang, ${ }^{8}$ Xiaojie Wang, ${ }^{9}$ \\ Binyou Wang, ${ }^{10}$ and Liming $\mathrm{Li}^{1}$ \\ ${ }^{1}$ Department of Epidemiology and Biostatistics, School of Public Health, Peking University Health Science Center, Beijing, \\ China \\ ${ }^{2}$ Qingdao Center for Diseases Control and Prevention, Qingdao, China \\ ${ }^{3}$ Zhejiang Center for Disease Control and Prevention, Hangzhou, China \\ ${ }^{4}$ Beijing Center for Disease Control and Prevention, Beijing, China \\ ${ }^{5}$ Shanghai Center for Disease Control and Prevention, Shanghai, China \\ ${ }^{6}$ Jiangsu Center for Disease Control and Prevention, Nanjing, China \\ ${ }^{7}$ Sichuan Center for Disease Control and Prevention, Chengdu, China \\ ${ }^{8}$ Tianjin Center for Disease Control and Prevention, Tianjin, China \\ ${ }^{9}$ Qinghai Center for Disease Control and Prevention, Xining. China \\ ${ }^{10}$ Harbin Medical University, Harbin, Heilongjiang China
}

\begin{abstract}
Twins reared apart provide a fascinating experiment to distinguish genetic from environmental influences. However, there is as yet no broad report on distribution of twins reared apart, especially in the Chinese population. In this study, information on 18,295 volunteer twin pairs of all age groups was compiled in nine provinces or cities of China, and questionnaires were used for zygosity determination. It was discovered that twins reared apart from 0 to 10 years of age accounted for $2.2 \%$ of all twin interviewees, with the proportion of this 0-10 group separated before 1, 2, and 5 years old, accounting for $65.3 \%, 76.1 \%$, and $91.3 \%$, respectively. The proportion of twins reared apart is not significantly related to zygosity or gender, but it is related to region and twin age. As the age of twins lowers, the proportion of those reared apart gradually decreases. Twins reared apart will become rarer in the future and therefore should be cherished as a resource.
\end{abstract}

Keywords: twin studies, child rearing, adoption, environment, genes

Classical twin design (CTD) estimates the parameters of additive genetic variance $\left(\mathrm{V}_{\mathrm{A}}\right)$, non-additive genetic variance $\left(\mathrm{V}_{\mathrm{NA}}\right)$, common environmental effect variance $\left(\mathrm{V}_{\mathrm{C}}\right)$, and unique environmental effect variance $\left(\mathrm{V}_{\mathrm{E}}\right)$ by comparing the similarities between monozygotic (MZ) twins and dizygotic (DZ) twins. Apart from these four parameters, the correlation coefficient $(r)$ of $\mathrm{DZ}$ twins attributable to non-additive genetic influence is also unidentified (Coventry \& Keller, 2005). However, CTD only obtains three observations: total phenotypic variance, $\mathrm{MZ}$ phenotypic covariance, and $\mathrm{DZ}$ phenotypic covariance. It is obviously impossible to deduce the five parameters from the three observations, since the degree of freedom will be negative when using structural equation models (Ozaki et al., 2011). We therefore must assume $r=1 / 4$ and $\mathrm{V}_{\mathrm{C}}$ or $\mathrm{V}_{\mathrm{NA}}=0$ to estimate the three other parameters. This is a potential limitation of CTD - bias - and often occurs during parameter estimation since $\mathrm{V}_{\mathrm{C}}$ and $\mathrm{V}_{\mathrm{NA}}$ cannot be estimated simultaneously while fixing $r$ at $1 / 4$ (Coventry \& Keller, 2005).

One way to address the problem is to study twins reared apart, which is an ingenious concept and known as 'the fascinating experiment of nature, the simplest and most powerful method for disentangling the influence of

RECEIVED 30 July 2014; ACCEPTED 28 January 2015. First published online 6 March 2015.

ADDRESS FOR CORRESPONDENCE: Li Liming, Department of Epidemiology and Biostatistics, School of Public Health, Peking University Health Science Center, Beijing 100191, China; E-mail: lmlee@vip.163.com 
environment and genetic factors on human characteristics' (Bouchard et al., 1990). It is also a rare resource for genetic epidemiology. The first advantage of the study lies in the resemblance between $\mathrm{MZ}$ twins reared apart (MZA) and this provides a direct estimate of trait heritability (Segal \& Mulligan, 2014). The second advantage is that, in theory, by simultaneously studying twins reared together and those reared apart, we can obtain information about total phenotypic variance, phenotypic covariance of MZA, phenotypic covariance of MZ twins reared together (MZT), phenotypic covariance of DZ twins reared apart (DZA), and phenotypic covariance of DZ twins reared together (DZT), which can help address the five pieces of unknown information in CTD.

Since twins reared apart are quite rare, and because it is difficult to get access to a large sample size, there are only a limited number of studies in the literature. This makes the currently remaining study on twins reared apart particularly valuable. This kind of study has already been initiated in Sweden, Australia, the United States, and Japan (Hayakawa et al., 2006), but in terms of distribution of twins separated early, there have been few study reports as of the present time. China has a large twin population, and according to a study conducted by Gan and Zheng (2002), in 1989 alone, 186,273 pairs of twins were born, accounting for $0.762 \%$ of newborns in the same year. Furthermore, Shandong, Henan, and Jiangsu were the top three provinces in China for twin birthrates, which were 1.391\%, 1.066\%, and $0.949 \%$, respectively (Gan \& Zheng, 2002). Due to the application of assisted reproductive technologies in recent years, the number of twins is expected to rise. Despite such rich twin resources in China, no study on twins reared apart has been fully conducted. In 2011, Peking University analyzed a small number of twins reared apart in the Chinese National Twin Registry (CNTR) for a pilot study, discovering that three pairs of twins out of 505 pairs in Qingdao, Shandong, were reared apart and 27 pairs out of 503 in Lishui, Zhejiang, were reared apart, accounting for $0.6 \%$ and $5.4 \%$ respectively of the total (Gao et al., 2011). Given such a large range, the sample size needs to be further expanded to encompass a large area. Thus, the CNTR conducted a cross-sectional study in nine provinces or cities in China to understand the approximate distribution of twins reared apart.

\section{Materials and Methods}

The CNTR collected twin information in Beijing, Tianjin, Heilongjiang, Shanghai, Jiangsu, Zhejiang, Sichuan, Qinghai, and Qingdao between November 2011 and April 2013. The nine provinces or cities ranged from the north, south, east, and west of China. The researchers recruited twin volunteers, mainly through local centers for disease control (CDCs) and prevention, which represented nonprobability sampling. Due to differences in twin birthrate and workforce capability in CDCs, the sample size of different provinces differed greatly. Inclusion criteria included all age groups, both genders, MZ or DZ, and permanent residents of the place of investigation. Exclusion criteria were people with a severe physical disability or those who could not officially sign the informed consent. The study passed the ethical review of Peking University Biomedical Ethics Committee (IRB00001052-11029).

The twins were interviewed in person by trained investigators. The question 'Have you ever been apart for more than one year?' was asked. If the answer was yes, further questions were asked, including at what age they were separated, for how many years they were apart in total, and habitation status after separation. The separation was defined as not living in the same family for a continuous period of more than 1 year.

The questionnaire information was inputted to the dedicated CNTR client terminals and compressed data files were encrypted and then uploaded onto the CNTR data center to ensure safety of data transmission. Quality control included random selection of $10 \%$ of the questionnaires for secondary data entry as well as random selection of $10 \%$ of interviewees for a repeat interview to ensure data consistency between the two occasions.

Questionnaires for gender, age, and whether a twin pair looked like 'two peas in a pod' were used for twin zygosity diagnosis. Genes were tested among 191 twin pairs for evaluation of the accuracy of the questionnaire method, which discovered that the DZ accuracy (sensitivity) was $0.806, \mathrm{MZ}$ accuracy (specificity) 0.903 , and the area under ROC curve 0.89 .

SPSS20.0 was utilized for data analysis. Means, medians, and percentages were calculated for statistical description, and $\chi^{2}$ test and logistic regression were adopted for statistical inference.

\section{Results}

\section{Description of All Twins Recruited}

In the CNTR, 18,295 twin pairs and triplets were interviewed. See Figure 1 for their detailed distribution. A large portion of these twin pairs and triplets were distributed in Shandong province, and the rest were in Beijing, Tianjin, Heilongjiang, Shanghai, Jiangsu, Zhejiang, Sichuan, and Qinghai. Among them, 10,209 pairs were MZ twins (56.7\%); 8,846 pairs were male twins (48.5\%), 5,654 female twins $(31.0 \%)$, and 3,668 were twins of opposite sex $(20.1 \%)$. Qingdao had the lowest average age of 22.3 years old and Zhejiang the highest of 42.0 years old (Table 1).

\section{Distribution of Twins Reared Apart}

Among all pairs of twins, 407 were separated when $0-10$ years old, including $227 \mathrm{MZ}$ pairs, $177 \mathrm{DZ}$ pairs, as well as three pairs with zygosity unknown, accounting for $2.2 \%$ of 


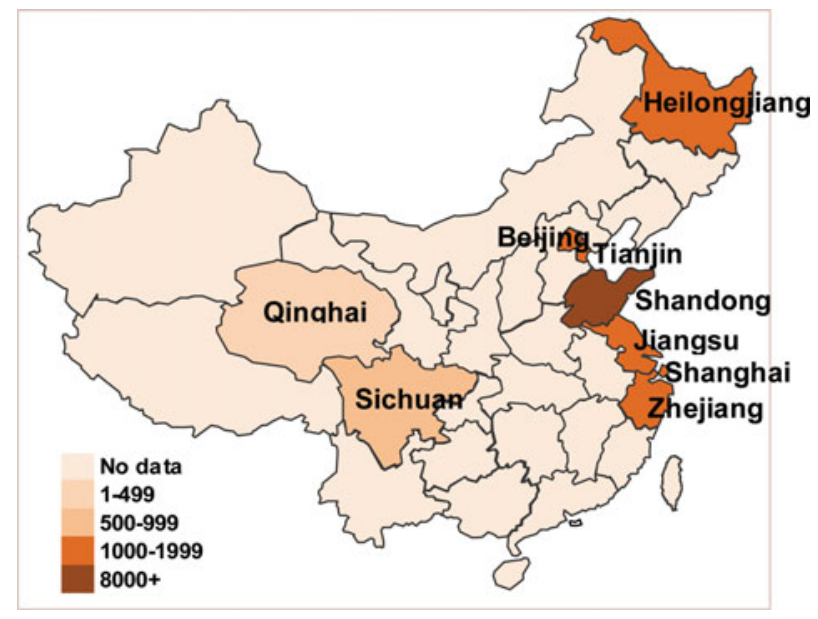

FIGURE 1

(Colour online) Distribution of twins by region (pairs).

TABLE 1

Distribution of Twins by Zygosity, Gender, Age, and Region*

\begin{tabular}{|c|c|c|c|c|c|c|c|c|c|c|c|c|c|c|c|c|}
\hline \multirow[b]{4}{*}{ Province/City } & \multicolumn{4}{|c|}{ Zygosity } & \multicolumn{10}{|c|}{ Gender } & \multicolumn{2}{|c|}{ Age (year) } \\
\hline & & & & & & & & & & & & & & & & \\
\hline & \multicolumn{2}{|c|}{$\mathrm{MZ}$} & \multicolumn{2}{|c|}{ DZ } & \multicolumn{2}{|c|}{ MM } & \multicolumn{2}{|c|}{$\mathrm{FF}$} & \multicolumn{2}{|c|}{ MF } & \multicolumn{2}{|c|}{ Same sex } & \multicolumn{2}{|c|}{ Opposite } & \multirow[b]{2}{*}{ Average age } & \multirow[b]{2}{*}{$S D$} \\
\hline & $N$ & (\%) & $N$ & (\%) & $N$ & (\%) & $N$ & (\%) & $N$ & (\%) & $N$ & (\%) & $N$ & (\%) & & \\
\hline Beijing & 893 & (53.4) & 780 & (46.6) & 672 & $(40.1)$ & 613 & (36.6) & 388 & (23.2) & 2 & $(0.1)$ & 1 & $(0.1)$ & 34.5 & 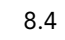 \\
\hline Tianjin & 557 & (54.8) & 460 & (45.2) & 597 & $(58.6)$ & 235 & (23.1) & 185 & (18.2) & 0 & $(0.0)$ & 1 & $(0.1)$ & 39.5 & 11 \\
\hline Heilongjiang & 667 & $(57.0)$ & 503 & $(43.0)$ & 535 & $(45.6)$ & 400 & (34.1) & 236 & (20.1) & 3 & $(0.3)$ & 0 & $(0.0)$ & 39.3 & \\
\hline Shanghai & 692 & $(49.2)$ & 715 & (50.8) & 584 & $(41.4)$ & 550 & (39.0) & 273 & (19.4) & 0 & $(0.0)$ & 2 & $(0.2)$ & 40.0 & 10.9 \\
\hline Jiangsu & 1,101 & $(59.2)$ & 758 & (40.8) & 968 & (51.9) & 550 & (29.5) & 341 & (18.3) & 2 & $(0.1)$ & 3 & $(0.2)$ & 39.7 & 11 \\
\hline Zhejiang & 961 & (62.9) & 568 & (37.1) & 841 & (54.9) & 426 & (27.8) & 262 & (17.1) & 1 & $(0.1)$ & 1 & $(0.1)$ & 42.0 & 12 \\
\hline Sichuan & 415 & $(54.6)$ & 345 & (45.4) & 405 & $(52.9)$ & 205 & $(26.8)$ & 150 & (19.6) & 1 & $(0.1)$ & 5 & $(0.7)$ & 39.1 & 10.9 \\
\hline Qinghai & 259 & (52.1) & 238 & (47.9) & 276 & (55.4) & 119 & (23.9) & 103 & (20.7) & 0 & $(0.0)$ & 0 & $(0.0)$ & 39.8 & \\
\hline Qingdao & 4,664 & $(57.6)$ & 3430 & (42.4) & 3968 & $(47.8)$ & 2556 & (30.8) & 1,730 & (20.8) & 32 & $(0.4)$ & 23 & $(0.3)$ & 22.3 & 16.6 \\
\hline Total & 10,209 & $(56.7)$ & 7797 & (43.3) & 8846 & $(48.5)$ & 5654 & (31.0) & 3,668 & (20.1) & 41 & $(0.2)$ & 36 & $(0.2)$ & 31.4 & 16.1 \\
\hline
\end{tabular}

Note: ${ }^{2} 289$ pairs with unknown zygosity, 50 pairs with missing gender information, and 4 pairs with missing age information. MM: male twins; FF: female twins; MF: twins of opposite sex.

all twin interviewees. The age of separation had a skewed distribution. Twins separated before they were 1, 2, and 5 years accounted for $65.3 \%, 76.1 \%$, and $91.3 \%$ respectively of all twins separated before 11 years (Table 2).

\section{Correlated Factors of Distribution of Twins Reared Apart}

In order to analyze if twins/triplets, gender, zygosity, age, or region are correlated with distribution of twins reared part, $\chi^{2}$ tests were conducted respectively and the results are as follows.

The difference in the proportion of twins reared apart when they were $0-10$ years old in twins $(2.2 \%)$ and triplets $(2.5 \%)$ was not statistically significant $\left(\chi^{2}<0.001, d f=1\right.$, $p=1.000)$; the difference in the proportion in twins of the same gender $(2.2 \%)$ and twins of opposite gender $(2.3 \%)$ was not statistically significant $\left(\chi^{2}=0.197, d f=1, p=\right.$ $.657)$; and the difference in the proportion of male twins
$(2.0 \%)$ and female twins $(2.5 \%)$ was likewise not statistically significant $\left(\chi^{2}=3.096, d f=1, p=.078\right)$. Similarly, the difference in the proportion of twins reared apart between MZ twins (2.2\%) and DZ twins (2.3\%) was not statistically significant $\left(\chi^{2}=0.044, d f=1, p=.834\right)$.

The difference in the distribution of twins reared apart among different age groups, however, was statistically significant $\left(\chi^{2}=40.498, d f=6, p<.001\right)$. As shown in Table 3, the group aged 60 or higher occupied the largest proportion and those separated when they were $0-10$ years old accounted for $4.6 \%$ of all twin interviewees; the group aged below 10 occupied the smallest proportion, which was only $1.4 \%$. As the age rose, the share of twins reared apart exhibited linear growth (linear-by-linear association $\chi^{2}=$ 33.150, $d f=1, p<.001$; see Figure 2).

At the same time, the differences in distribution of twins reared apart among different regions were also statistically significant $\left(\chi^{2}=109.628, d f=8, p<.001\right)$. Qingdao had 
TABLE 2

Age Distribution of Twins Separated When They Were 0-10 Years Old

\begin{tabular}{|c|c|c|c|c|c|}
\hline $\begin{array}{l}\text { Age of separation } \\
\text { (year) }\end{array}$ & MZA (\%) & DZA (\%) & $\begin{array}{l}\text { Zygosity } \\
\text { unknown (\%) }\end{array}$ & Total (\%) & $\begin{array}{l}\text { Accumulative } \\
\text { percentage (\%) }\end{array}$ \\
\hline 0 & $14(6.1)$ & $12(6.8)$ & $0(0.0)$ & $26(6.3)$ & 6.3 \\
\hline 1 & 133 (58.6) & $104(58.8)$ & $3(100.0)$ & $240(59.0)$ & 65.3 \\
\hline 2 & $24(10.6)$ & $20(11.3)$ & $0(0.0)$ & $44(10.8)$ & 76.1 \\
\hline 3 & $20(8.8)$ & $16(9.0)$ & $0(0.0)$ & $36(8.8)$ & 84.9 \\
\hline 4 & $7(3.1)$ & $4(2.3)$ & $0(0.0)$ & $11(2.7)$ & 87.6 \\
\hline 5 & $11(4.8)$ & $4(2.3)$ & $0(0.0)$ & $15(3.7)$ & 91.3 \\
\hline 6 & $3(1.3)$ & $2(1.1)$ & $0(0.0)$ & $5(1.2)$ & 92.5 \\
\hline 7 & $2(0.9)$ & $5(2.8)$ & $0(0.0)$ & $7(1.7)$ & 94.2 \\
\hline 8 & $6(2.6)$ & $4(2.3)$ & $0(0.0)$ & $10(2.5)$ & 96.7 \\
\hline 9 & $5(2.2)$ & $1(0.6)$ & $0(0.0)$ & $6(1.5)$ & 98.2 \\
\hline 10 & $2(0.9)$ & $5(2.8)$ & $0(0.0)$ & $7(1.7)$ & 100.0 \\
\hline Total & $227(100.0)$ & 177 (100.0) & $3(100.0)$ & 407 (100.0) & 100.0 \\
\hline
\end{tabular}

\section{TABLE 3}

Distribution of Twins Reared Apart Among Different Age Groups

\begin{tabular}{lccl}
\hline Age group & $\begin{array}{l}\text { Number of twins separated } \\
\text { before 11 years old (pairs) }\end{array}$ & $\begin{array}{l}\text { Number of twins } \\
\text { recruited (pairs) }\end{array}$ & Percentage (\%) \\
\hline $0-$ & 34 & 2,365 & 1.4 \\
$10-$ & 32 & 1,950 & 1.6 \\
$20-$ & 74 & 3,890 & 1.9 \\
$30-$ & 103 & 4,529 & 2.3 \\
$40-$ & 86 & 3,551 & 2.4 \\
$50-$ & 47 & 1,339 & 3.5 \\
$60-$ & 31 & 6667 & 4.6 \\
Total & 407 & 18,291 & 2.2 \\
\hline
\end{tabular}

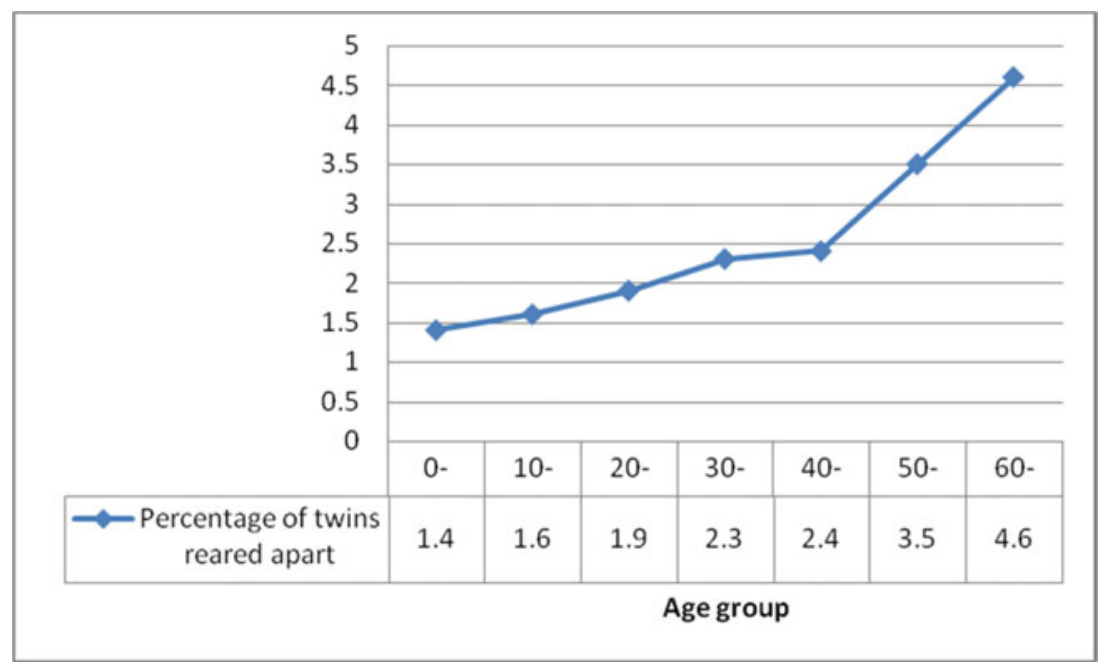

\section{FIGURE 2}

(Colour online) Percentage of twins reared apart among different age groups (\%).

the lowest percentage, with twins separated when they were $0-10$ years old accounting for $1.4 \%$ of all twin interviewees; Zhejiang had the highest percentage at $4.4 \%$ (Table 4 , Figure 3).

Given the correlation between age and region in this study (Qingdao had the lowest average age and Zhejiang the highest), age and region were simultaneously included in logistic regression. Zygosity and gender were likewise analyzed. Similar to the univariate analysis, this approach showed that zygosity and gender were not significantly correlated with whether twins were reared apart or not, but age and region were statistically significant. As age increased, the possibility of twins being reared apart increased. Compared with Qingdao, the proportion of twins reared apart in Zhejiang, Beijing, and Shanghai was significantly higher (Table 5). 
TABLE 4

Distribution of Twins Reared Apart Across Nine Provinces/Cities

\begin{tabular}{lccc}
\hline Province/city & $\begin{array}{l}\text { Number of twins separated } \\
\text { before 11 years old (pairs) }\end{array}$ & $\begin{array}{l}\text { Number of twins } \\
\text { recruited (pairs) }\end{array}$ & Percentage (\%) \\
\hline Zhejiang & 68 & 1,531 & 4.4 \\
Beijing & 68 & 1,676 & 4.1 \\
Shanghai & 54 & 1,410 & 3.8 \\
Qinghai & 12 & 499 & 2.4 \\
Jiangsu & 40 & 1,866 & 2.1 \\
Sichuan & 16 & 766 & 2.1 \\
Heilongjiang & 19 & 1,174 & 1.6 \\
Tianjin & 15 & 1,018 & 1.5 \\
Qingdao & 115 & 8,355 & 1.4 \\
Total & 407 & 18,295 & 2.2 \\
\hline
\end{tabular}

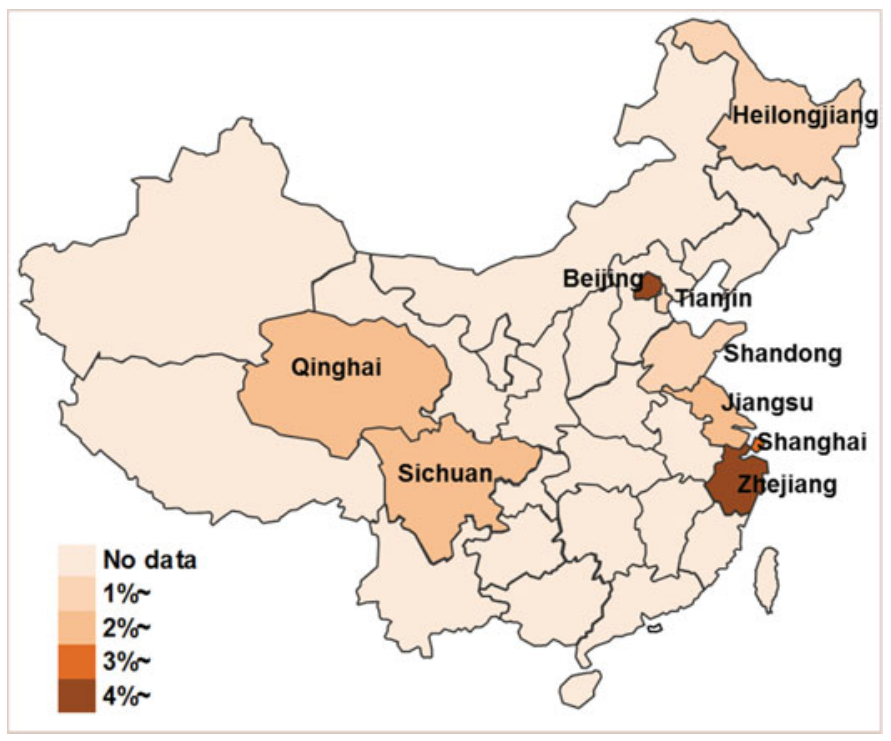

FIGURE 3

(Colour online) Percentages of twins reared apart across nine provinces/cities.

TABLE 5

Logistic Regression Analysis on Age and Region (Compared With Qingdao)

\begin{tabular}{|c|c|c|c|c|c|c|}
\hline Independent variable & $B$ & S.E. & Wals & $d f$ & $p$ & $\operatorname{Exp}(B)$ \\
\hline Age & 0.011 & 0.004 & 8.741 & 1 & .003 & 1.011 \\
\hline Region & & & 70.932 & 8 & $<.001$ & \\
\hline Zhejiang & 0.985 & 0.170 & 33.413 & 1 & $<.001$ & 2.677 \\
\hline Beijing & 0.966 & 0.160 & 36.279 & 1 & $<.001$ & 2.627 \\
\hline Shanghai & 0.854 & 0.178 & 22.918 & 1 & $<.001$ & 2.350 \\
\hline Qinghai & 0.384 & 0.313 & 1.508 & 1 & .220 & 1.468 \\
\hline Jiangsu & 0.265 & 0.195 & 1.857 & 1 & .173 & 1.304 \\
\hline Sichuan & 0.231 & 0.276 & 0.703 & 1 & .402 & 1.260 \\
\hline Heilongjiang & -0.020 & 0.256 & 0.006 & 1 & .938 & 0.980 \\
\hline Tianjin & -0.107 & 0.283 & 0.142 & 1 & .707 & 0.899 \\
\hline Constant term & -4.633 & 0.207 & 498.751 & 1 & $<.001$ & 0.010 \\
\hline
\end{tabular}

\section{Situation Post-Separation}

In a further analysis on duration of the separation of twins, the median duration of separation was 8 years and the median of the age of twins upon being reunited was 11 years. There were 183 pairs apart for more than 10 years, accounting for $46.3 \%$ of all twins reared apart, beginning when they were $0-10$ years old.

Regarding living arrangements for twins after they were separated, the majority of them lived in different homes of the same county $(71.8 \%)$, while only a small number of 
twins were raised in different counties (16.9\%), provinces (9.9\%), and even countries (1.3\%).

\section{Discussion}

MZA and DZA can provide a new perspective that other perspectives fail to offer (Segal \& Mulligan, 2014). Regarding the percentage of twins reared apart in the total population, however, there have been few studies conducted in this framework. This is the first attempt in the Chinese population.

As shown in the CNTR, a total of 407 pairs of twins were separated before they were 11 years old, accounting for $2.2 \%$ of the 18,295 pairs of twin interviewees. Qingdao had the lowest percentage of twins reared apart at $1.4 \%$, while Zhejiang had the highest at $4.4 \%$. Since the CNTR was a system for twin volunteers, and because we utilized a non-probability sampling approach, the results of this study cannot be inferred to other populations. The results, however, appear consistent with those of another study conducted by our research team 3 years ago, when it was found that twins reared apart accounted for $0.6 \%$ and $5.4 \%$ of the total in Qingdao (Shandong Province) and Lishui (Zhejiang Province), respectively (Gao et al., 2011).

An important factor that affects the proportion of twins reared apart is how to define the age of separation, which has not yet been generally recognized. Out of the studies on twins reared apart, two projects are influential. The first is the Swedish Adoption/Twin Study of Aging (SATSA), which selected twins in the Swedish Twin Registry who were separated at an early age in childhood. SATSA collected information on a total of 351 pairs of twins reared apart (Pedersen et al., 1991). The median age of separation was 2 years, and $75 \%$ were separated when they were 5 years old or younger (Svensson et al., 2003). As defined by SATSA, being reared apart referred to separation before 11 years old, but it was also recognized that twins reared apart before the ages of 1, 2, and 5 exhibited a highly skewed distribution, accounting for $52 \%, 69 \%$, and $82 \%$ of all twins reared apart (Kendler et al., 2000). The second was the Minnesota Study of Twins Reared Apart (MISTRA), which vertically studied and traced twins separated in early childhood who grew up in different families and reunited in adulthood. In this study, twins had to have been separated by four years of age. The mean age at separation was 0.60 years and ranged from 0.00 to 4.50 years. (Hur et al., 1998; Segal, 2012). MISTRA collected information on 81 pairs of MZA and 56 pairs of DZA (Segal, 2012). We adopted the definition of SATSA, namely being separated before 11 years old. We found the age of separation was also exhibiting a skewed distribution, similar to SATSA and MISTRA, and the median was 1 year old. Twins reared apart before they turn 1,2, and 5 years account for $65.3 \%, 76.1 \%$, and $91.3 \%$ respectively of all twins reared apart before they turn 11 years old.
The median duration of separation was 8 years and the median age upon reunion was 11 years old. This was noticeably different from SATSA, which found that the median age of reunion was 19 years (Svensson et al., 2003). This meant a large proportion of twins in the CNTR returned to the same family before they became adults and could potentially share a common rearing environment. After separation, $71.8 \%$ of twins still lived in the same district or county, but in different families, and only a small number were raised in different counties, provinces, or countries. This differs from the research of MISTRA, which indicated that the majority of twins lived in the United States and England and some came from Australia, Canada, Germany, Israel, Netherlands, New Zealand, South Africa, and Sweden (Segal, 2012). Given the large population in China, twins reared apart in the CNTR mainly came from the Chinese mainland.

This study did not find a correlation between zygosity and gender with twins reared apart, meaning it could not be said that twins of a certain zygosity or gender were more likely to be reared apart. However, age and region were discovered to be correlated with the proportion of twins reared apart, and, in particular, their age. As age grew, the proportion experienced linear growth. This implies that it is easier to find twins reared apart as ages increase. There could be two reasons for this phenomenon. The first could be due to economic influence. The other could be Chinese child policy in the past. Twins might be adopted by relatives or friends without children because their parents could not raise twins in a poor family or they had already had too many children. This is different from the MISTRA study, in which twins were separated mainly because of illegitimate birth $(44.5 \%)$ and financial limitations (13.1\%) (Segal, 2012). At present, China is in a transformative stage. Under the influence of both rapid economic growth and the one child policy, twins become a pleasant surprise for the majority of families and are therefore more likely to grow up within the same family. Thus, although twins reared apart are a valuable resource for genetic epidemiological studies, they are rarer and more difficult to find. This makes the currently available resources involving twins reared apart more valuable, and these resources should be fully utilized by researchers. As for the regional distribution, we found only limited information based on this study. Zhejiang, Beijing, and Shanghai, the top three provinces/cities, are all in the east of China. However, Qingdao (Shandong Province), with the lowest percentage of twins separated when they were 0-10 years old, is also an eastern region. In addition, Zhejiang and Shanghai are in southern of China, while Beijing is in the north. Further investigation is necessary in order to answer questions about regional distribution.

It should be noted that the twins in the CNTR were all aware that they were reared apart. Individuals unaware of their reared-apart status were clearly excluded. Therefore, 
the actual proportion of twins reared apart might be higher than that found in this study.

\section{Conclusion}

In conclusion, twins reared apart for more than 1 year when they were younger than 11 years old accounted for $2.2 \%$ of all twin interviewees in the CNTR. As the age of twins lowers, the share of those reared apart gradually decreases. Twins reared apart will become rarer in the future and therefore they should be cherished as a resource.

\section{Acknowledgments}

We are grateful for the assistance from Professor Nancy L. Pedersen for the questionnaire design. We also appreciate all the contributions from the graduate students at Peking University, especially Ms Biqi Wang, Ms Chunxiao Liao, Ms Qingqing Liu, Ms Zhuqing Bao, Ms Luanluan Sun, Ms Feng Zhang, Ms Chenxi Qin, and the faculty in related CDCs in nine provinces or cities. This work was supported by the National Natural Science Foundation of China (81202264); the China Medical Board (01-746); and special research funding for the public welfare industry of health, China (201002007).

\section{References}

Bouchard, T. J., Lykken, D. T., McGue, M., Segal, N. L., \& Tellegen, A. (1990). Sources of human psychological differences: The Minnesota study of twins reared apart. Science, 250, 223-228.

Coventry, W. L., \& Keller, M. C. (2005). Estimating the extent of parameter bias in the classical twin design: A comparison of parameter estimates from extended twin-family and classical twin designs. Twin Research \& Human Genetics, 8, 214-223.
Gan, J., \& Zheng, J. (2002). Regional distribution of birth rates of twins in China. China Public Health, 18, 658-659.

Gao, W., Li, L., Cao, W., Zhan, S., Lv, J., Pang, Z., ... Hu, Y. (2011). A comparative study on blood pressure, obesity, smoking and alcohol drinking behavior in Chinese twins reared apart and together. Journal of Peking Unversity (Health Sciences), 43, 329-332.

Hayakawa, K., Kato, K., Onoi, M., Hayashi, C., Yang-Ping, C., Kanamori, M., ... Kadota, K. (2006). The Japanese study of adult twins reared apart and growing old separately. Twin Research \& Human Genetics, 9, 806-807.

Hur, Y. M., Bouchard, T. J., \& Eckert, E. (1998). Genetic and environmental influences on self-reported diet: a reared-apart twin study. Physiology \& Behavior, 64, 629636.

Kendler, K. S., Thornton, L. M., \& Pedersen, N. L. (2000). Tobacco consumption in Swedish twins reared apart and reared together. Archives of General Psychiatry, 57, 886892.

Ozaki, K., Toyoda, H., Iwama, N., Kubo, S., \& Ando, J. (2011). Using non-normal SEM to resolve the ACDE model in the classical twin design. Behavior Genetics, 41, 329-339.

Pedersen, N. L., McClearn, G. E., Plomin, R., Nesselroade, J. R., Berg, S., \& DeFaire, U. (1991). The Swedish adoption twin study of aging: an update. Acta Geneticae Medicae et Gemellologiae, 40, 7-20.

Segal, N. L. (2012). Born together - Reared apart: The landmark Minnesota twin study. Cambridge, UK: Harvard University Press.

Segal, N. L., \& Mulligan, C. A. (2014). Twins reunited: Scientific and personal perspectives. Twin Research \& Human Genetics, 17, 134-136.

Svensson, D. A., Larsson, B., Waldenlind, E., \& Pedersen, N. L. (2003). Shared rearing environment in migraine: Results from twins reared apart and twins reared together. Headache, 43, 235-244. 